interested in the comparative or cross-national study of foreign policy phenomena. Even as a relatively small Section, it has had comparative panels as well as American panels. Given the growing interest in the topic of democracy and foreign policy, it seems particularly appropriate to focus both on the extent to which we can generalize from the American case to cases involving other societies and to the extent that the experiences of other democratic societies can be instructive for us.

By emphasizing domestic sources, the Section seeks to include those analysts who are primarily concerned with the role that particular institutions play in making foreign policy. Students of the presidency, the executive branch, parliaments and legislatures, courts, the press, and interest groups as well as students of elections, federalism, etc., who have a special interest in the way in which these institutions relate to foreign policy, are welcome in the renamed Section.

The Section also hopes to attract those who are primarily interested in decision making in foreign policy. The influence of organizations, small groups, and individuals on foreign policy choices is becoming an increasingly recognized source of explanation in foreign policy. This is especially true when the foreign policy analyst needs to understand why particular outcomes occur.

Of course, the enlargement of the Section is meant to enhance, not diminish, the importance of public opinion as a source of foreign policy. After all, public opinion is the final arbiter of values in domestic society. Groups and individuals in various institutions may from time to time claim to represent the public on matters of foreign policy, but their legitimacy in a democracy, at least in the long run, is based on their capacity for representing public opinion accurately and completely.

The renamed Section has also placed special emphasis on including individuals and groups other than professional political scientists in its activities. A number of active pollsters and opinion analysts are members of the Section, and we hope to enhance the interprofessional character of the Section by encouraging historians, economists, sociologists, and journalists as well as government and nongovernment leaders to join.

In addition to organizing panels and workshops for the annual conferences of the American Political Science Association and planning awards for outstanding research and writing on foreign policy, the Section has developed an e-mail network. For those who are interested in joining our e-mail network, the following instructions are provided:

From BITNET, send mail to "listserv@uga"

From INTERNET, send mail to “listserv@uga.cc.uga.edu”

First line of mail message being: subscribe POFP-L first-name

last-name Doe

example: subscribe POFP-L John

The Section offers both a list (POFP-L) and a journal (POFP-J). The list is a bulletin-board and is mainly for the exchange of messages. The journal is designed to give access to more permanent files, such as bibliographies, syllabi, research projects, etc. Individuals can subscribe to the POFP-J by substituting a $J$ for the $L$ in the guidelines provided above.

Members of the APSA may join Section 31: Domestic Sources of Foreign Policy by remitting $\$ 5$ to the APSA. Non-political scientists interested in joining the section may become Associate Members of the APSA for $\$ 25$. For additional information, please contact Bill Chittick, Section Chair, Department of Political Science, University of Georgia, Athens, GA 30602. Other possible contacts include: Barbara Bardes, University of Cincinnati; Lisa Brandes, Tufts University; Ralph Carter, Texas Christian University; Thomas Graham, Rockefeller Foundation; Ron Hinckley, Research/Strategy/ Management, Inc.; Alan Kay, Americans Talk Issues Foundation; Andy Katz, Denison University; Mary
McIntosh, USIA; Phil Powlick, Depauw University; and Richard Sobel, Princeton University.

\section{United States Information Agency Supports Summer Institutes on the American Political System}

The United States Information Agency awarded grants in 1994, as in 1993, to the American University and the American Political Science Association for an institute in Washington, D.C., for 18 scholars, each from a different country, and to Southern Illinois University for an institute for 18 Russian scholars. Descriptions of these institutes follow and are accompanied by pictures of the participants. Participants in both programs are enrolled as APSA members in 1995.

\section{The AU/APSA}

\section{Summer Institute}

Once again, the American University and the American Political Science Association made use of Washington, D.C., to offer a program that featured presentations by political scientists along with elected and appointed officials, journalists, and lobbyists. Trips were made to Philadelphia and Annapolis where the visiting faculty toured the city and Maryland's capital and heard from city and state officials and scholars of urban and state politics.

The 1994 Summer Institute was directed by Philip Brenner, Chair, Department of International Politics and Foreign Policy at American University. James A. Thurber, Director of the Center for Congressional and Presidential Studies in AU's School of Public Affairs, directed the program's unit on Congress. Jeff Fishel, Professor, School of Public Affairs, directed a unit on the presidency and the executive branch. Sheilah Mann, Director of Education Programs at APSA, 


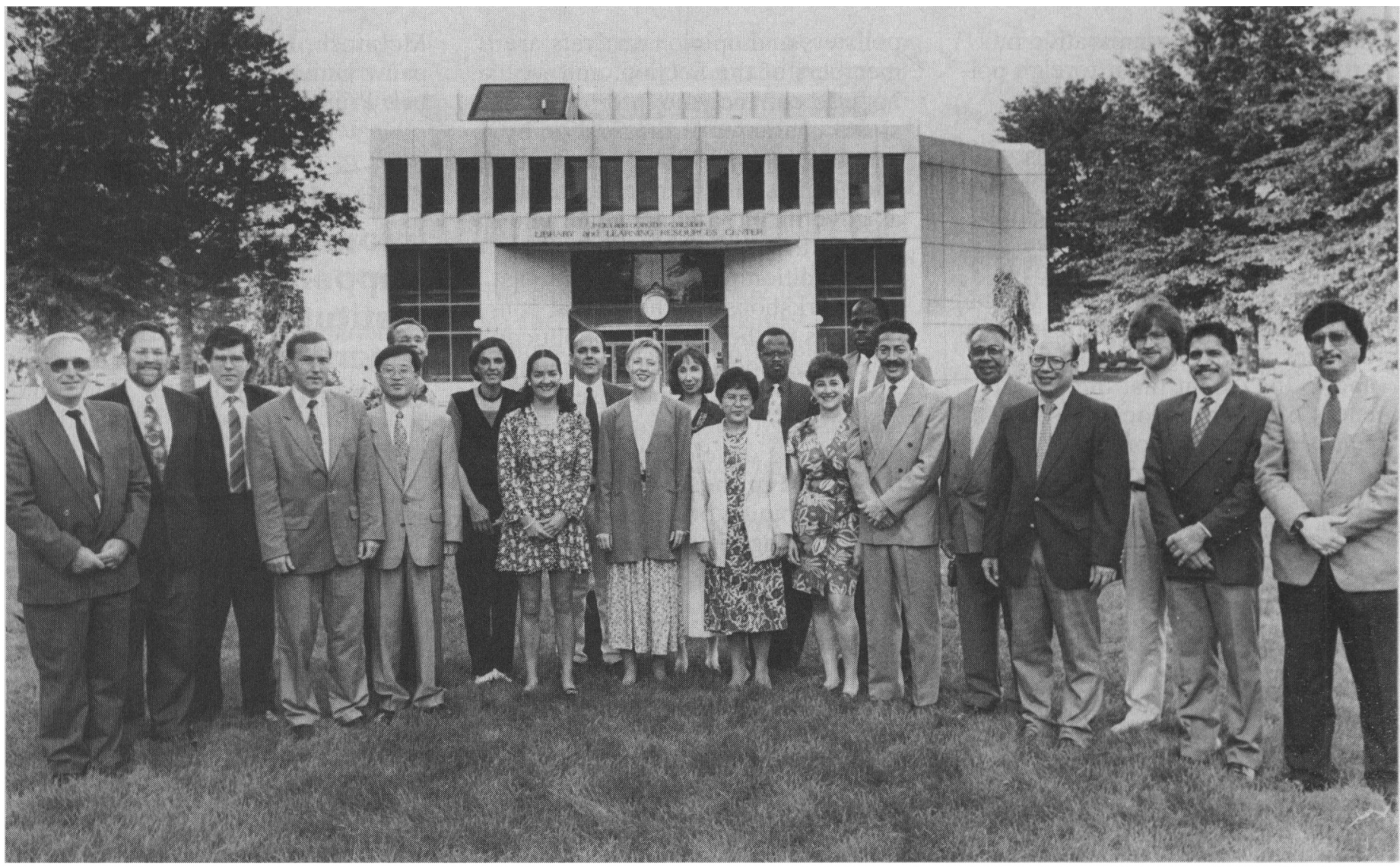

Participants and directors in the AU/APSA Summer Institute are pictured here. From left to right: Muhyi Nashashibi, Philip Brenner, Gergely Egedy, Romuald Holly, Chan-Wook Park, Bob Reinalda, Martha Bonham, Juny Montoya, Renato Lessa, Annika Stenlund, Sheilah Mann, Belen Tangco, Amukowa Anangwe, Nevine Loutfi, Kumi Ansah-Koi, Oscar Valles, Ghulam Chaudhry, M.R. Prudhisan Jumbala, Gediminas Vitkus, Roman Villicana, Waheed Hashem.

served as the Institute's Education Director and was responsible for the unit on constitutional democracy. Philip Brenner also coordinated the unit on American foreign policy.

The Institute participants were faculty or advanced graduate students in political science, international relations and law. They came from countries in Africa, Latin America, Western and Eastern Europe, the Middle East, Asia, and South Asia. Their names and affiliations are:

Renato de Andrade Lessa, Rio De Janeiro University Research Institute, Brazil

Juny Montoya, Colombia, University of the Andes

Nevine Mounir Tawfik Loutf, American University in Cairo

Kumi Ansah-Koi, Ghana, University of Ghana

Gergely Egedy, Hungary, School of Public Administration-Budapest
Muhyi Eddin Izzat Nashashibi, Jordan, Yarmouk University

Amukowa Anangwe, Kenya, University of Nairobi

Chan-Wook Park, Korea, Seoul National University

Gediminas Vitkus, Lithuania, University of Vilnius

Roman "Lopez" Villicana, University of the Americas, Mexico

Bob Reinalda, University of Nijmegen, The Netherlands

Ghulam Mustafa Chaudhry, Pakistan, Bahauddin Zakariya University, Pakistan

Belen Lorezca Tangco, Philippines, University of Santo Tomas

Romuald Jacek Holly, Poland, Polish Academy of SciencesWarsaw

Waheed Hamzah Abdullah Hashem, Saudi Arabia, King Abdulaziz University

Annika Stenlund, Sweden, UMEA University
M.R. Prudhisan Jumbala, Thailand, Chulalongkorn University

Oscar Jose Cerero Valles, University of the Andes, Venezuela

\section{The Institute at Southern Illinois University}

Southern Illinois University at Carbondale will play host this summer to an institute for 18 international scholars. This institute will cover a broad gamut of subjects dealing with American government and politics and law at the graduate level for scholars who teach in these fields in their home country. The participants will all be from Russia and they are from a broadly representative range of universities including Moscow State University, St. Petersburg Electrotechnology University, St. Petersburg University, and Tomsk University. These scholars are chosen for participa- 


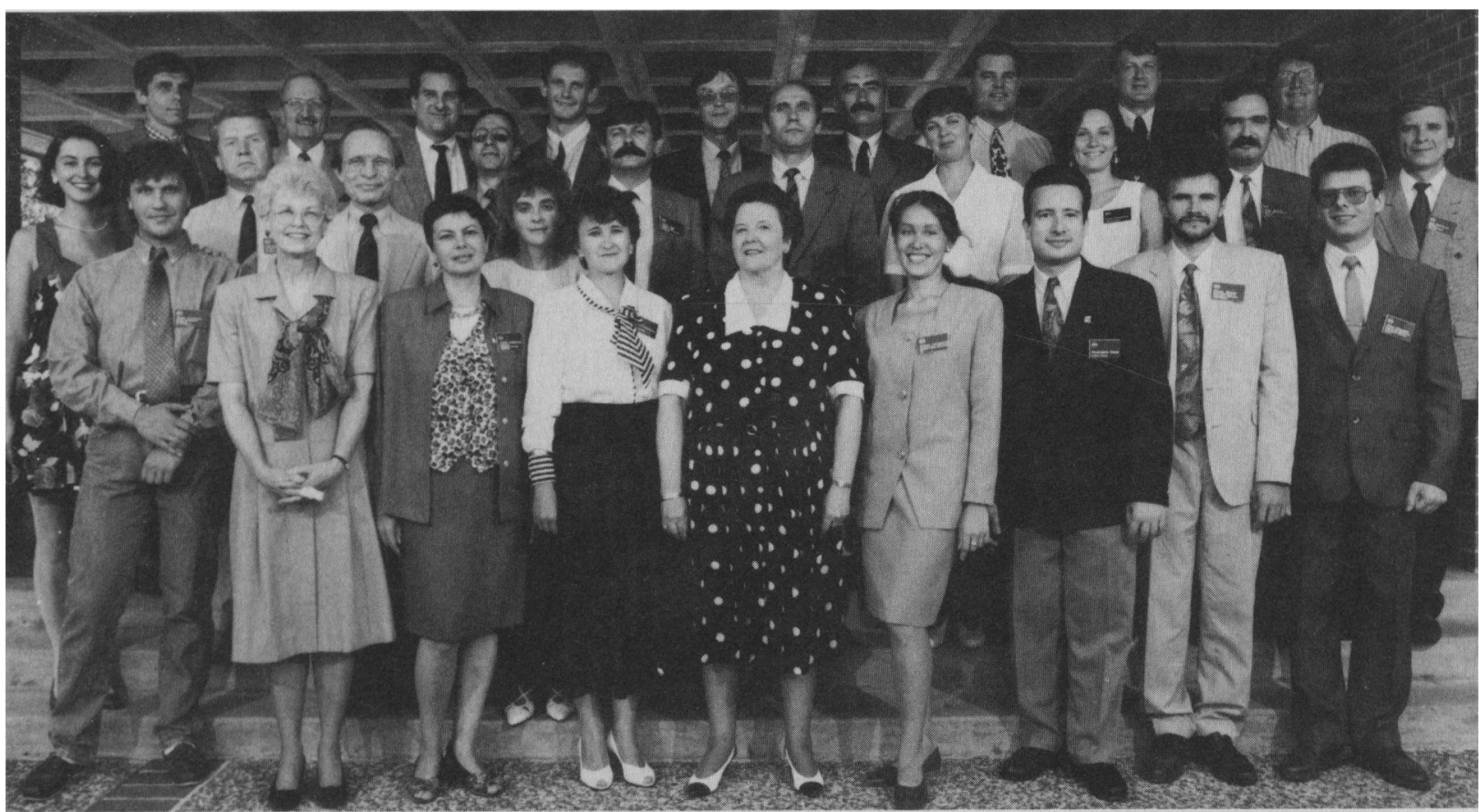

Southern Illinois University/APSA participants, directors, and staff: First row (from left to right): Sergei Fyodorov, Nancy Jackson, Victoria Romanova, Natalya Luchinina, Rosie Brown, Dilara Ayupova, Chris Cripps, Sergey Mamay, Alexei Khomitch. Second row (from left to right): Irina Filippova, Alexander Korushkin, John Jackson, Igor Barygin, Elena Pritchina, Victor Panin, Valery Zakharov, Alla Kassianova, Irena Feofanova, Sergei Zasorin, Igor Kiselyov. Third row (from left to right): Aleksei Polyakov, Linz Brown, Mike Esler, Vitaly Ermakov, Yuri Kuznetsov, Mikhail Shlakhtin, Bryan Dexter, Dick Kuehl, Jim Leibert. Note: Nancy Jackson, Rosie Brown, Chris Cripps, Bryan Dexter, Dick Kuehl, and Jim Leibert were Institute staff. John Jackson was Director and Linz Brown was Co-Director of the Institute.

tion in the institute because of their crucial assignments in their own universities, teaching courses about the United States and developing curriculum which their colleagues will use.

The objectives of the institute include:

(1) Providing the participants with an overview of the major subjects in American government and politics, and constitutional and legal studies. This will be done in a series of lectures and discussions led by the faculty of the Department of Political Science and the School of Law.

(2) Introducing the participants to major components of the American culture and exploring the culture's impact on American government and politics. This will be accomplished through a series of trips to St. Louis, Missouri; Chicago and Springfield, Illinois; and Washington, D.C. These trips will be supplemented by visits to local Carbondale area events like the 4th of July celebration and the SIUC summer playhouse musicals.

(3) Developing curricular materi- als that the participants can use in enhancing their teaching once they return to Russia. This objective will be accomplished under the leadership of a faculty member from the Department of Curriculum and Instruction at SIUC.

The institute is funded by a grant from the United States Information Agency (USIA) in Washington, D.C. It is jointly administered by Dean John S. Jackson of the College of Liberal Arts, Dean Harry Haynsworth of the School of Law, and Linz Brown of International Programs and Services. The faculty coordinators are Barbara L. Brown and Michael Esler of the Department of Political Science and Thomas McAffee of the School of Law.

This year's participants included:

Dilara Ayupova, Bashkiria State University

Igor Nikolaevich Barygin, St. Petersburg Electrotechnology University

Vitaly Viktorovich Ermakov, Samara State University Sergei Jegor Fyodorov, Herzen Pedagogical University
Alla Anatolievna Kassianova, Russian-American College at Tomsk State University

Alexei Khomitch, Moscow State Institute for International Relations

Igor Kisselyov, Yaroslavl State University

Alexander Korushkin, St. Petersburg University

Yuri Kuznetsov, Orel Pedagogical Institute

Natalya Luchinina, Tver State University

Sergey Petrovich Mamay, Urals Professional and Pedagogical University

Victor Nikolaevich Panin, Pyatigorsk State Pedagogical Institute of Foreign Languages

Elena Pritchina, Altai State University

Victoria Romanova, Khabarovsk Pedagogical University

Mikhail Yurievich Shlakhtin, Taganrog State University of Radio Engineering

Aleksei Polyakov, Russian State Humanities University 


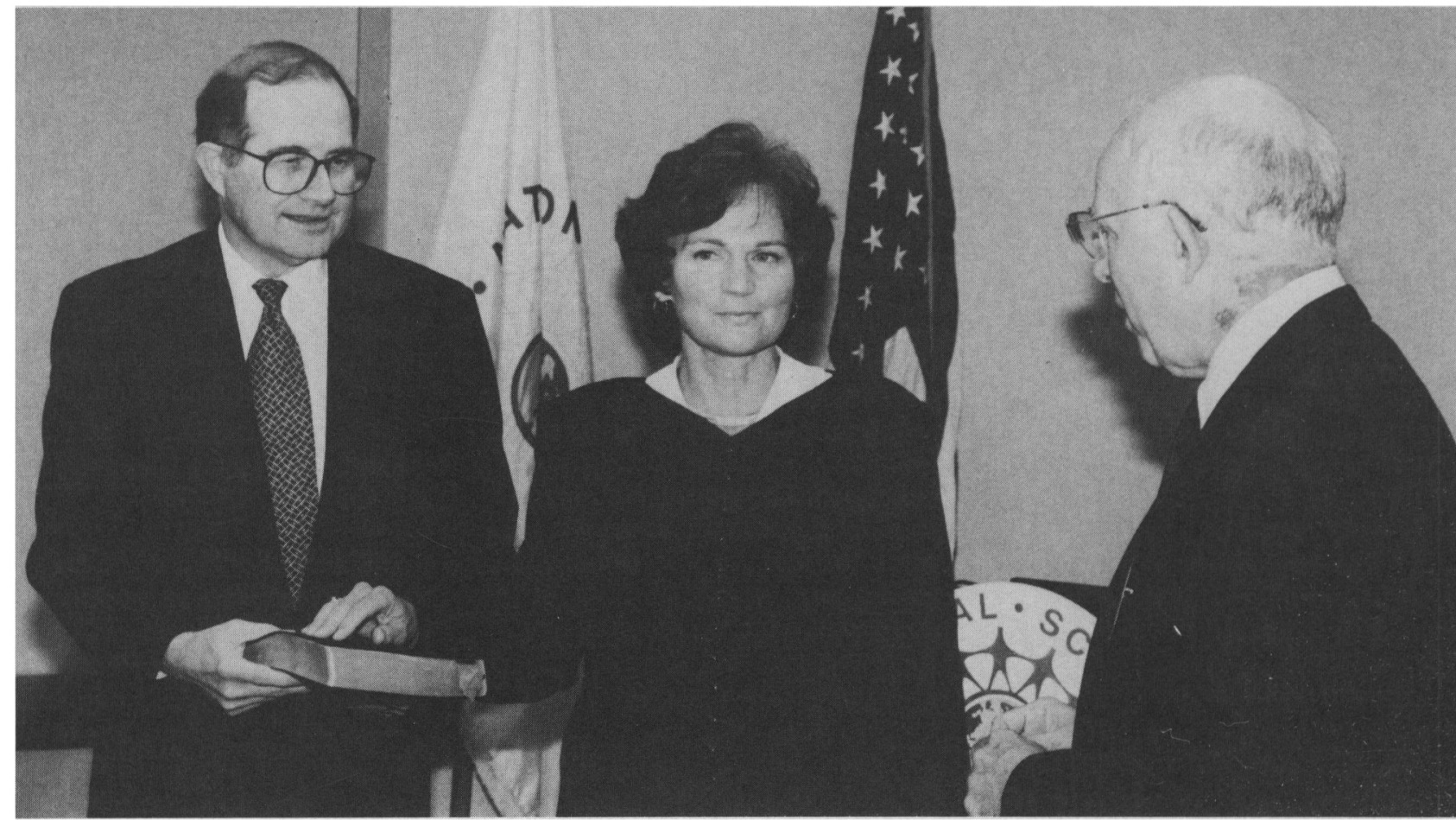

Anne Peterson being sworn in as new deputy director of the National Science Foundation by Presidential Science Advisor John Gibbons ( $\mathrm{r}$ ) and NSF Director Neal Lane (1).

Valery Zakharov, Nizhny

Novgorod Institute of Foreign

Languages

Sergei Zasorin, Moscow State Pedagogical University.

\section{Peterson Named Deputy Director, NSF}

Anne Peterson has assumed the position of deputy director of the National Science Foundation following a ceremony August 18, 1994. Peterson, who will also serve as chief operating officer, becomes the first woman in the agency's history to hold either of its top two posts. Formerly Vice President for Research and Dean of the Graduate School at the University of Minnesota, Peterson will now oversee the NSF's daily operations and implementation of government-wide system reforms. Peterson was nominated by President Clinton and following her confirmation by the Senate was administered the oath of office by Presidential Science Advisor John Gibbons.

\section{Write Congress on Behalf of the Social Sciences and the Humanities}

The American Political Science Association is a member of the Consortium of Social Science Associations, whose mission is to educate lawmakers about the nature and uses of social science. COSSA also lobbies funds for social science research shown primarily in the National Science Foundation budget. Likewise, the Association is a member of the National Humanities Alliance, whose purpose is to promote public awareness of lobby for research funds in the humanities as shown in the budget of the National Endowment for the Humanities. Members of Congress ask how NSF and NEH serve the country, their states and districts; some members also ask what purposes social science and the humanities, in general, and political science, in particular, serve.

Members of Congress should hear from their constituents that
National Science Foundation and National Endowment for the $\mathrm{Hu}$ manities funding has been used in their districts. APSA reminds members that it is important, both upon receipt of an NSF or NEH grant and upon completion of the grant, to write a letter to their senators and representatives. The letters will remind members of Congress that voters in their states and districts benefit from NSF and NEH funding. Such communications will also educate members of Congress as to the work of political scientists.

\section{Forty-Second Class of Congressional Fellows Begins 1994-95 Program}

Winners of the 1994-95 Congressional Fellowship Program competition for political scientists, journalists and federal employees were announced in the September 1994 issue of this publication.

In addition, medical professionals and international participants have 